\title{
Una nota sobre la economía venezolana durante la post-crisis 2007-2009
}

\section{Gabriel Delgado Toral*}

El pasado quince de enero del año en curso fue un día histórico para el pueblo venezolano. Luego de diecisiete años el partido en el poder fue desplazado en la Asamblea Nacional por la mayoría opositora, que triunfara en las elecciones de diciembre del año pasado, en el marco del decreto por el que el presidente Nicolás Maduro se otorgó poderes discrecionales. A pesar de ello, el presidente venezolano pretendía una vez más, con la declaratoria de estado de emergencia nacional, legislar otra vez discrecionalmente durante dos meses ante la crisis económica que desde hace varios años se vive en el país. Ante esta situación, el presente artículo analiza brevemente el comportamiento de algunas variables económicas: el producto y la inflación, el comportamiento del precio internacional del petróleo y de las reservas internacionales.

En primera instancia, a pesar de que el gobierno ha ocultado desde hace tiempo los datos económicos relevantes "porque el pueblo venezolano no puede ni debe conocer", luego de la crisis internacional 2007-2009 el comportamiento del producto interno bruto (PIB) ha sido bastante desigual: dos períodos de alzas durante 2007-2008 y durante 2010-2012 y dos períodos de bajas durante 20092010 y 2014-2015, estas dos últimas de -4 y $-10 \%$, de acuerdo con el Fondo Monetario Internacional (FMI). La muy alta inflación que ridículamente insinúa el régimen que es "inducida desde Colombia y Miami" no ha cesado, incluso ha aumentado drásticamente: según datos oficiales en 2015 la inflación fue de poco más de 141\% aunque el FMI estimó que para ese mismo año el dato fue de $250 \%$ y prevé una inflación de $720 \%$ para 2016 (véase Gráfica 1).

La catástrofe económica tiene otros flancos. No obstante que Venezuela posee una de las principales reservas de crudo mundiales tiene dos problemas, principalmente: 1) se redujo la producción de barriles en los últimos años debido a que el modelo económico no ha dedicado la inversión necesaria en el sector -que se intensificó con la huelga de los trabajadores de Petróleos de Venezuela en 2002-2003- al grado de estar importando petróleo de Estados Unidos desde 2014 y 2) el problema de la caída del precio del petróleo que inició a mediados de 2014 y del cual son casi $100 \%$ dependientes -de acuerdo con la Organización Mundial de Comercio- para la gestión de las finanzas públicas (véase Gráfica 2). 


\section{Gráfica I}

Venezuela: PIB real e inflación, 2007-2015^

$-\Delta \%$ anual-

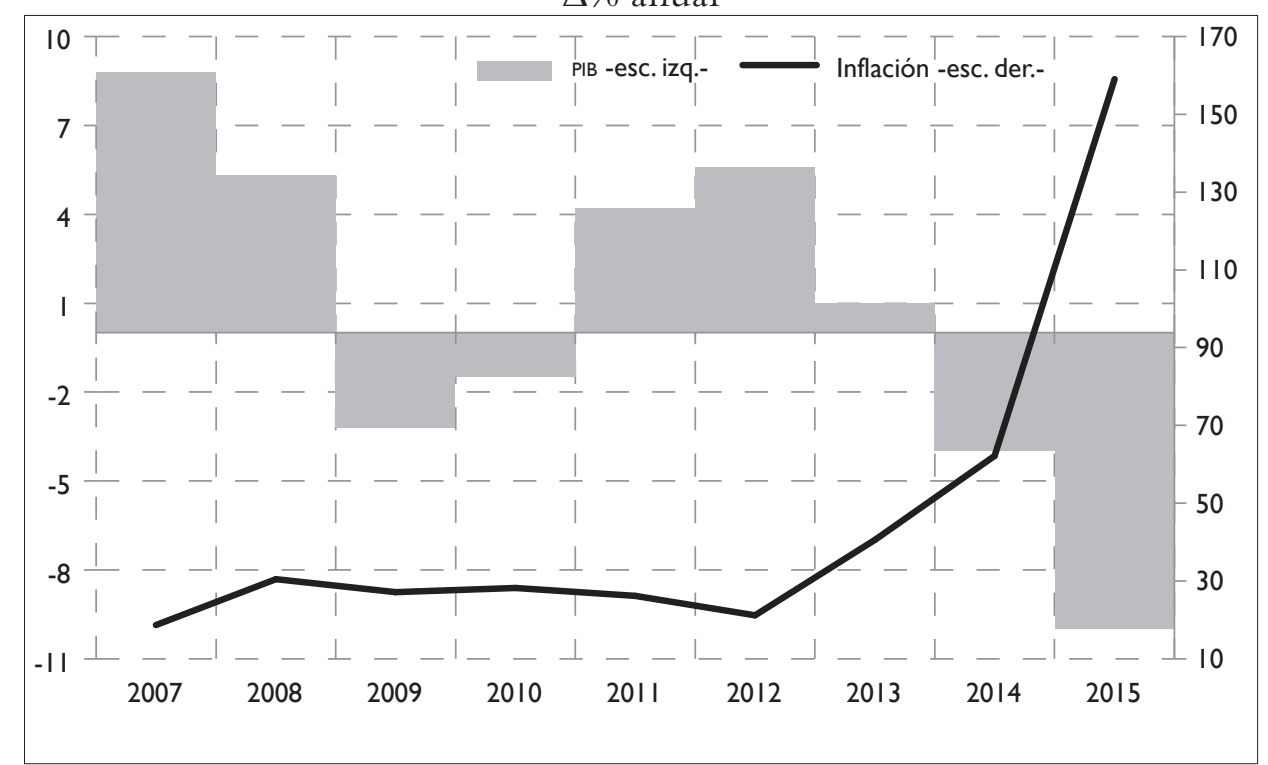

* Las cifras de 2014 y 2015 son proyecciones del FMI.

Fuente: elaboración propia con datos del IMF, 2016.

\section{Gráfica 2}

Venezuela: reservas internacionales

y precio internacional de petróleo crudo, 2007-2015

-millones de dólares y dólares por barril-

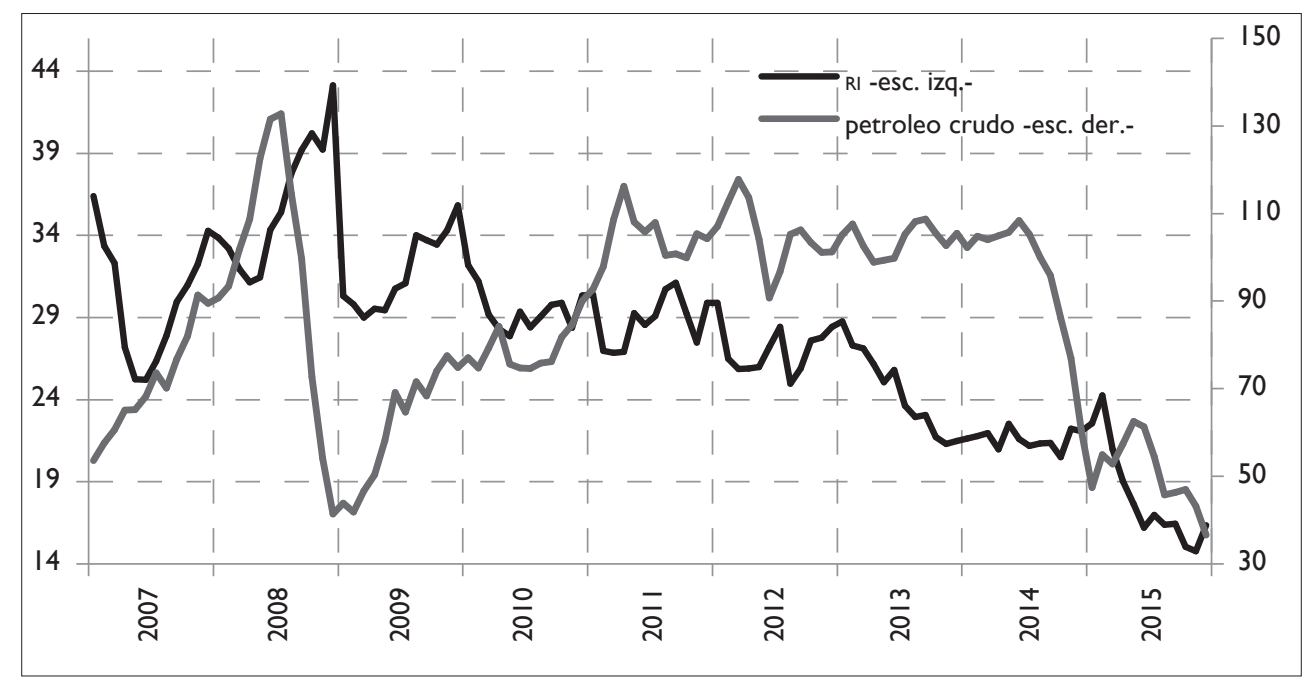

* Las cifras de 2014 y 2015 son proyecciones del FMI.

Fuente: elaboración propia con datos del Banco Central de Venezuela, 2016a y del World Bank, 2016. 
Por otro lado, las reservas internacionales han tenido un comportamiento bajista desde finales de 2008 hasta diciembre de 2015, al pasar de 43127 a 16361 millones de dólares, una caída de más de $60 \%$ (véase Gráfica 2). En línea con el Convenio Cambiario núm. 11 que dicta las normas que establecen el régimen para la adquisición de divisas por parte del sector público, el banco central ha entregado \$220 $397 \mathrm{mi}$ llones de dólares durante 2007-2013 (hasta donde el gobierno permite obtener los datos) para los requerimientos del sector público y privado, es decir, 85\% del total de divisas (que fueron de $\$ 256300$ millones de dólares). El instituto emisor también destinó \$7 552 millones para los pagos de la deuda externa y \$22 799 millones para el manejo de las existencias del Tesoro Nacional a través de las cuentas mantenidas en el Banco Central de Venezuela (véase Cuadro 1).

El Convenio Cambiario también establece que el banco central otorgará divisas al sector público para: a) pagos y remesas indispensables al servicio exterior de la República de los Poderes Ejecutivo, Legislativo, Judicial, Ciudadano y Electoral en misiones especiales; $b$ ) erogaciones a las cuales está obligada la República en virtud de tratados y acuerdos internacionales; c) pagos referidos a la seguridad pública y defensa nacional; d) pago de la deuda pública externa de la República; e) gastos de viáticos de funcionarios públicos que viajen en misiones oficiales al exterior y $f$ ) las divisas que requiera la República para el manejo de las existencias del Tesoro Nacional a través de las cuentas mantenidas en el Banco Central de Venezuela.

Pero el problema del capitalismo de estado instaurado por el chavismo en Venezuela es más estructural. A pesar de que el precio internacional del petróleo crudo se elevó durante 2009-2010 y luego se mantuvo estable desde 2011 hasta la mitad de 2014 las reservas internacionales del país seguían cayendo desde principios de 2009 (véase Gráfica 2), lo que manifiesta que la debacle del modelo venezolano no se explica porque cayó el precio internacional del petróleo y de la producción petrolera, con la consecuente menor entrada de divisas en ese rubro -incluso en el período de bonanza económica tampoco mejoró el desempeño de la economía. Esto se entiende en parte por las "importantes transferencias de productos energéticos hacia los demás países de la región (principalmente Cuba y los que integran el Mercosur) a cambio de alimentos" (Delgado, 2014) y en parte por la sumisión al arcaico régimen económico-político de La Habana. 


\section{Cuadro I}

Venezuela: destino de las divisas del banco central al sector público, 2007-2013

-millones de dólares-

\begin{tabular}{|c|c|c|c|c|c|c|}
\hline año & $\begin{array}{c}\text { requerimientos del } \\
\text { sector público y } \\
\text { privado }\end{array}$ & $\begin{array}{c}\text { pagos de } \\
\text { la deuda } \\
\text { externa }\end{array}$ & $\begin{array}{l}\text { manejo de las existen- } \\
\text { cias del TN1/ a través } \\
\text { de las cuentas mante- } \\
\text { nidas en el BCV2/ }\end{array}$ & & otros & total \\
\hline 2007 & 38950 & 445 & 500 & 1985 & $\begin{array}{l}1500 \text { solicitados por PDVSA3/; } \\
250 \text { para la Corporación Inte- } \\
\text { ramericana de Inversiones; } 125 \\
\text { para el Banco de Desarrollo del } \\
\text { Caribe; } 110 \text { a operaciones de la } \\
\text { Corporación Andina de Fomento }\end{array}$ & 41880 \\
\hline 2008 & 38950 & 66 & 4590 & - & - & 43606 \\
\hline 2009 & 28925 & 54 & 5300 & 324.77 & $\begin{array}{l}100 \text { para importaciones ordi- } \\
\text { narias; } 60 \text { al sector público; } 146 \\
\text { para tarjeta de crédito y } 18.77 \\
\text { para casos especiales, estudiantes, } \\
\text { genérico y otras remesas }\end{array}$ & 34604 \\
\hline 2010 & 22025 & 133 & 3220 & - & - & 25378 \\
\hline 2011 & 33990 & 103 & 5000 & 310 & $\begin{array}{l}310 \text { para Corporación de Abaste- } \\
\text { cimiento y Servicios Agrícolas }\end{array}$ & 39403 \\
\hline 2012 & 34750 & 3476 & 3500 & 1377 & $\begin{array}{l}1170 \text { que podrían ser utilizados } \\
\text { para compromisos acumulados } \\
\text { del sector público y privado; } \\
112 \text { corresponden a la solicitud } \\
\text { del Consejo Nacional Electoral; } \\
65 \text { para el BANDES4/ corres- } \\
\text { pondientes a desembolsos de los } \\
\text { proyectos "Línea 5, tramo Plaza } \\
\text { Venezuela - Miranda II" y "Línea } \\
2 \text { El Tambor - San Antonio de } \\
\text { los Altos", de conformidad con } \\
\text { la solicitud realizada por dicho } \\
\text { organismo; } 30 \text { corresponden a } \\
\text { Pequiven }\end{array}$ & 43103 \\
\hline 2013 & 22807 & 3275 & 689 & 1555 & $\begin{array}{l}550 \text { correspondientes a las liqui- } \\
\text { daciones asociadas al SUCRE5/; } \\
405 \text { solicitados por el BANDES; } \\
400 \text { millones que podrían ser } \\
\text { utilizados para compromisos } \\
\text { acumulados del sector público y } \\
\text { privado; } 200 \text { para la liquidación } \\
\text { de las asignaciones a través del } \\
\text { SICAD6/ }\end{array}$ & 28326 \\
\hline ubtotales & 220397 & 7552 & 22799 & 5552 & & $\begin{array}{c}\text { total } \\
256300\end{array}$ \\
\hline
\end{tabular}

Notas: 1/ Tesoro Nacional; 2/Banco Central de Venezuela; 3/Petróleos de Venezuela; 4/Banco de Desarrollo Económico y Social de Venezuela; 5/Sistema Unitario de Compensación Regional de Pagos; 6/Sistema Complementario de Administración de Divisas.

Fuente: elaboración propia con datos de las Decisiones del Directorio en Materia Monetaria, Cambiaria y Financiera, Banco Central de Venezuela, 2016b. 
Todo lo anterior se suma a una lista larga y compleja de problemas que ha tenido Maduro en su todavía corta estancia en el Palacio de Miraflores: la brutalidad policial con la que el régimen combate las protestas de diversa índole, los presos políticos que han surgido de ellas y la violación de los derechos humanos de distintas figuras y de sus familias (como la de Leopoldo López), la fallida política macroeconómica del "modelo chavista" que ha seguido el país desde hace poco más de tres lustros sumado al control de cambios que impera desde 2003 -y que ha generado la creación de mercados negros-, la escasez y el desabasto de productos básicos (alimentos, medicamentos, etc.) y de productos para las diferentes ramas industriales (papel para periódico, etc.). ¿Hasta cuándo durará el capitalismo de estado seguido por el mandatario venezolano? Ya se verá en las próximas semanas.

\section{Referencias}

Banco Central de Venezuela (2016a), Información estadística, Caracas.

--- (2016b), Legislación y decisiones del Directorio, Caracas.

Delgado, Gabriel (2014), "Venezuela: de economía y complots, 2005-2013", Economía Informa núm. 384, enerofebrero.

International Monetary Fund (2016), World Economic Outlook, Washington.

World Bank (2016), Global Economic Monitor Commodities, Washington.

Diario El país (2013-2016), diversas notas, varias fechas, Madrid.

Diario El universal (2013-2016), diversas notas, varias fechas, México.

Diario Excélsior (2013-2016), diversas notas, varias fechas, México.

Diario Reforma (2013-2016), diversas notas, varias fechas, México. 